\title{
Application of Auto-Switched Capacitor Bank to Mitigate Voltage Collapse Problem in Distribution System; a Case Study of Osogbo South -Western, Nigeria.
}

\author{
Okelola, M. O. \\ Department of Electronic \& Electrical Engineering, Ladoke Akintola University of Technology, P.M.B. \\ 4000, Ogbomoso, Nigeria
}

\begin{abstract}
:
Exponential demand for electrical power supply caused by increased use of electricity at both domestic and industrial level pose threat to power system stability. The need to enhance power system with adequate compensation via reactive power supply becomes a necessity. This paper therefore presents application of auto-switched capacitor bank to mitigate voltage collapse problem; a case study of Osogbo South-Western, Nigeria. The proposed approach carefully design the correct size of capacitor required to supply the reactive power needed for compensation. The obtained values were used to model the power system. The modeled system was subjected to disturbances with a view to investigate its performance. The results obtained showed that the designed capacitor bank was able to stabilize the voltage on the line despite the heavy loads on the power system.
\end{abstract}

Keywords: 33/11kV feeders, Auto-switched capacitor bank, Disturbance, Power factor improvement, Reactive power compensation, Voltage collapse

\section{Introduction}

Modern transmission systems of today demand that amount of reactive power support in the system should be increased to mitigate attendant consequences of inadequate reactive power supply on the system [1]. In reactive power control and management discrete controllers such as autoswitch capacitor bank are still vital pieces of device that are capable of injecting reactive power needed for compensation [2]. Adequate reactive power compensation offered salient benefits to the power system which includes voltage regulation (voltage control within acceptable limits), system power losses reduction brought about by power factor improvement and it increases the utilization of connected pieces of equipment at the consumer end, improves reliability of transmission system and more importantly efficiency of real power made available at the consumer end improved greatly $[2,3]$.

Prominent and frequent manifestation of effect of inability of power system to provide adequate reactive power is voltage instability [4].Voltage instability is noticed when disturbances inform increase in load demand with or without a variation of system conditions result in a continuous and uncontrollable system voltage drop [5]. It needs to be stressed that ignoring reactive power compensation on the system causes voltage collapse which is a path way to black out experienced around the world $[2,6]$. Voltage collapse on the other hands occurred as a result of inability of power system to supply the reactive power; it can as well be due to excessive absorption of reactive power by the power system itself [7]. 
Auto- switch capacitor banks employed delay time usually within the range of $30-40$ seconds between steps and the essence of this delay time is to ensure that the capacitors have discharged prior to being re-connected [8]. Appropriate choice of the delay time goes a long way in determining the accuracy and efficiency of auto-switch capacitor bank; long delay time limits its ability to track rapidly changing loads while slow response time may likely cause an overload condition in filter banks [8].

An auto-switch capacitor bank is a growing trend in providing power factor correction and improving system power factor. It is highly beneficial both to the power system and end users electrical/ electronic equipment. Its benefit to power system revolves around reduction in apparent power drawn from the ac source which in turn saves energy and minimizes the transmission losses and to the consumers; it is a mean of evading charges levied on them by the utilities company as a result of excessive reactive power consumed. Also, the electrical equipment operates correctly and reliably without being damaged or stressed when system power factor is close to unity [9]. On a general note, auto-switch capacitor offers increased serviceability, accurately display the power factor and other metered parameters, indicate alarm conditions, and lower the total installed cost [9].

This paper therefore presents application of auto-switched capacitor bank to mitigate voltage collapse problem on distribution system; a case study of Osogbo South-Western, Nigeria. The rest of this paper is organized as follows: Section 2 presents study location. Section 3 presents the materials and methods. Section 4 presents results and discussion while section 5 presents the conclusion and recommendation for future work.

\section{Study Location: Osogbo South-Western, Nigeria.}

In this study, the power system used as a case study is the Ibadan electricity distribution company (IBEDC) in Nigeria. Seven feeders were selected for analysis in Osogbo which belong to the control axis of IBEDC. The selected feeders are Oshogbo Township 33/11 kV, Power-line $33 / 11 \mathrm{kV}$, Prism 33/11kV, Water Works 33/11 kV, Osogbo-Ikirun Township 33/11kV, Nigeria Machine Tool (NMT) 33/11kV and Steel Rolling Mill (SRM) 33/11kV.

\section{Materials and Methods}

The data required for this analysis are installed capacity of each feeder, the calibrated load, voltage level, existing power factor and the implementation tool used is MATLAB/ SIMULINK.

\section{Analysis of Reactive Power Required for Compensation}

In this work, the power factor of each feeder of interest was raised to close to unity; the procedural computational steps taken are as shown below;

\section{Oshogbo Township 33/11 kV;}

Installed capacity $=62.50 \mathrm{MVA}$

Calibrated load $=25 \mathrm{MW}$;

The power factor for this feeder is calculated thus;

$$
\begin{aligned}
& \text { p.f }=\frac{P}{S}=\frac{25 \times 10^{6}}{62.50 \times 10^{6}}=0.40 \\
& \emptyset_{1}=\cos ^{-1}(0.40)=66.42^{\circ} \\
& Q_{1}=25 \tan 66.42^{\circ}=57.28 \mathrm{MVAR}
\end{aligned}
$$

If $\mathrm{P}=1.73 \mathrm{IV} \cos \emptyset$; then at $11 \mathrm{KV}$ voltage with the power factor improved from 0.4 to 0.95 . The reactive power is obtained thus;

$$
\begin{aligned}
& \emptyset_{2}=\cos ^{-1} 0.95=18.19 \\
& Q_{2}=25 \times 10^{6} \tan 18.19= \\
& 8.20 M V A R \\
& Q_{C}=Q_{1}-Q_{2}=57.28-8.20= \\
& \text { 49.07MVAR }
\end{aligned}
$$

\section{Power-line 33/11kV;}

Installed capacity $=30 \mathrm{MVA}$

Calibrated load $=20 \mathrm{MW}$

The power factor for this feeder is calculated thus

$$
\begin{aligned}
& \text { p.f }=\frac{P}{S}=\frac{20 \times 10^{6}}{30 \times 10^{6}}=0.66 \\
& \emptyset_{1}=\cos ^{-1} 0.66=48.19^{\circ} \\
& Q_{1}=20 \tan 48.19^{\circ}=22.36 \mathrm{MVAR}
\end{aligned}
$$

At $11 \mathrm{kV}$ voltage with the power factor improved from 0.66 to 0.95 . The reactive power is obtained thus

$$
\emptyset_{2}=\cos ^{-1} 0.95=18.19
$$


$Q_{2}=20 \times 10^{6} \tan 18.19=$

6.57MVAR

$Q_{C}=Q_{1}-Q_{2}=22.36 \quad-$

\section{Prison 33/11kV}

$=15.79 \mathrm{MVAR}$

Installed capacity $=36.50 \mathrm{MVA}$

Calibrated load $=27 \mathrm{MW}$

The power factor for this feeder is calculated thus;

$$
\begin{aligned}
& \text { p.f }=\frac{P}{S}=\frac{27 \times 10^{6}}{36.50 \times 10^{6}}=0.74 \\
& \emptyset_{1} \cos ^{-1}(0.74)=42.27^{\circ} \\
& Q_{1}=27 \tan 42.27^{\circ}=24.54 \mathrm{MVAR} \\
& P=1.73 \mathrm{IV} \cos \emptyset
\end{aligned}
$$

At $11 \mathrm{kV}$ voltage level with the power factor improved from 0.476 to 0.95 . The reactive power is obtained thus;

$$
\begin{aligned}
& \emptyset_{2}=\cos ^{-1} 0.95=18.19 \\
& Q_{2}=27 \times 10^{6} \tan 18.19= \\
& 8.87 M V A R \\
& Q_{C}=Q_{1}-Q_{3}=24.54-8.87= \\
& 15.67 \mathrm{MVAR}
\end{aligned}
$$

\section{Water Works 33/11 kV}

Installed capacity $=17.5 \mathrm{MVA}$

Calibrated load $=25 \mathrm{MW}$

The power factor for this feeder is calculated thus;

$$
\text { p.f }=\frac{P}{S}=\frac{25 \times 10^{6}}{25 \times 10^{6}}=1.0
$$

*Since the power factor is 1 , then no need for any compensation

\section{Osogbo / Ikirun Township 33/11kV}

Installed capacity $=36.5$ MVA

Calibrated load $=20 \mathrm{MW}$

The power factor for this feeder is calculated thus;

$$
\begin{aligned}
& \text { p.f }=\frac{P}{S}=\frac{20 \times 10^{6}}{36.50 \times 10^{6}}=0.55 \\
& \emptyset_{1}=\cos ^{-1} 0.55=56.77^{\circ} \\
& Q_{1}=20 \tan 56.77^{\circ}=30.53 \mathrm{MVAR}
\end{aligned}
$$

At $11 \mathrm{kV}$ voltage level with the power factor improved from 0.55 to 0.95 . The reactive power is obtained thus;

$$
\begin{aligned}
& \emptyset_{2}=\cos ^{-1} 0.95=18.19 \\
& Q_{2}=20 \times 10^{6} \tan 18.19= \\
& 6.57 M V A R \\
& Q_{C}=Q_{1}-Q_{2}=30.53-6.57 \\
& =23.96 \mathrm{MVAR}
\end{aligned}
$$

\section{Nigeria Machine Tool (NMT) 33/11kV}

Installed capacity $=15$ MVA
Calibrated load $=15 \mathrm{MW}$

The power factor for this feeder is calculated thus;

$$
\text { p.f }=\frac{P}{S}=\frac{15 \times 10^{6}}{15 \times 10^{6}}=1
$$

*Since the power factor is 1 , then no need for any compensation

\section{Steel Rolling Mill (SRM) 33/11kV}

Installed capacity $=40 \mathrm{MVA}$

Calibrated load $=15 \mathrm{MW}$

The power factor for this feeder is calculated thus;

$$
\begin{aligned}
& \text { p.f }=\frac{P}{S}=\frac{15 \times 10^{6}}{40 \times 10^{6}}=0.375 \\
& \emptyset_{1}=\cos ^{-1} 0.375=67.98^{\circ} \\
& Q_{1}=15 \tan 67.98^{\circ}=37.10 \mathrm{MVAR}
\end{aligned}
$$

At $11 \mathrm{kV}$ voltage levelwith the power factor improved from 0.375 to 0.95 . The reactive power is obtained thus;

$$
\begin{aligned}
& \emptyset_{2}=\cos ^{-1} 0.95=18.19 \\
& Q_{2}=15 \times 10^{6} \tan 18.19= \\
& 4.93 M V A R \\
& Q_{C}=Q_{1}-Q_{2}=37.10-4.93 \\
& =32.17 \mathrm{MVAR}
\end{aligned}
$$

Total $\mathbf{Q}_{\mathrm{C}}=49.07+23.96+15.67+15.79+$ 32.17

$$
=136.66 \mathrm{MVA}
$$

\section{For overall compensation}

Total calibrated load $=147 \mathrm{MW}$

Total installed capacity $=238 \mathrm{MVA}$

System power factor $=\frac{147}{238}=0.62$

$$
\begin{aligned}
& \emptyset_{1}=\cos ^{-1}(0.62)=51.86^{\circ} \\
& Q_{1}=\quad 147 \tan 51.86^{\circ}= \\
& 187.18 \mathrm{MVAR}
\end{aligned}
$$

At $11 \mathrm{kV}$ voltage level with the power factor improved from 0.62 to 0.95 . The reactive power is obtained thus;

$$
\begin{aligned}
& \emptyset_{2}=\cos ^{-1} 0.95=18.19 \\
& Q_{2}=147 \times 10^{6} \tan 18.19= \\
& 48.30 \mathrm{MVAR} \\
& Q_{C}=Q_{1}-Q_{2}=187.18-48.30= \\
& \text { 138.88MVAR }
\end{aligned}
$$

Modeling of the Power System with Voltage Collapse and Compensation

The developed system modeled using SIMULINK is as shown in Fig. 1. A disturbance load of 20MW was introduced into the transmission line. With the capacitor bank at stand-by, the behaviour of the power system was 
monitored from time $\mathrm{t}=0$ to time $\mathrm{t}=1 \mathrm{~s}$. The capacitor bank size required for compensation at the Oshogbo $33 \mathrm{kV}$ load bus is approximately 139MVAR as against a total of 142.46MVAR required at the distribution stations. The capacitor bank was placed on the $33 \mathrm{kV}$ transmission line rather than the $11 \mathrm{kV}$ line since larger amount of reactive power would be required in compensation because of installation cost as well as efficiency of the capacitor bank. Also, the capacitor bank size should be large enough to make the capacitive current greater than the inductive current since the supplied reactive power by capacitor decreases with the square of voltage; thus, a 210MVAR capacitor bank was placed on the $33 \mathrm{kV}$ transmission load bus.

The 210MVAR was split into three parallel sections of 70 MVAR each, and automatically switched separately according to the VAR compensation requirement of the loads to prevent system under voltage or over voltage which may lead to system collapse or equipment outage.

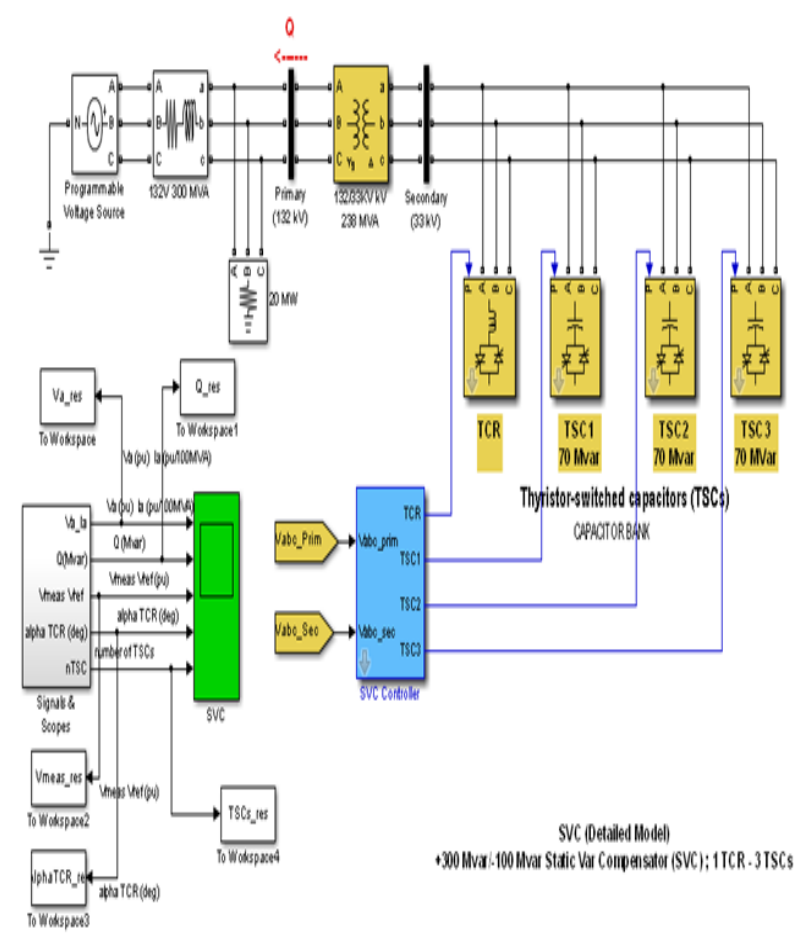

Figure 1: Simulink Modeled of 132/33kV

Transmission Line

\section{Results and Discussion}

Figure 2 presents the effect of voltage magnitude variation against the stipulated time of investigation. It was observed that there was a great disturbance on the system at time $0.4 \mathrm{~s}$ to $0.72 \mathrm{~s}$, making the amplitude of the waveform of the measured voltage to be around $0.9 \mathrm{pu}$. Based on the graphical illustration below between 0.4 and 0.5 seconds a smaller voltage magnitude of less than 1.0 p.u and -1.0 p.u was observed.

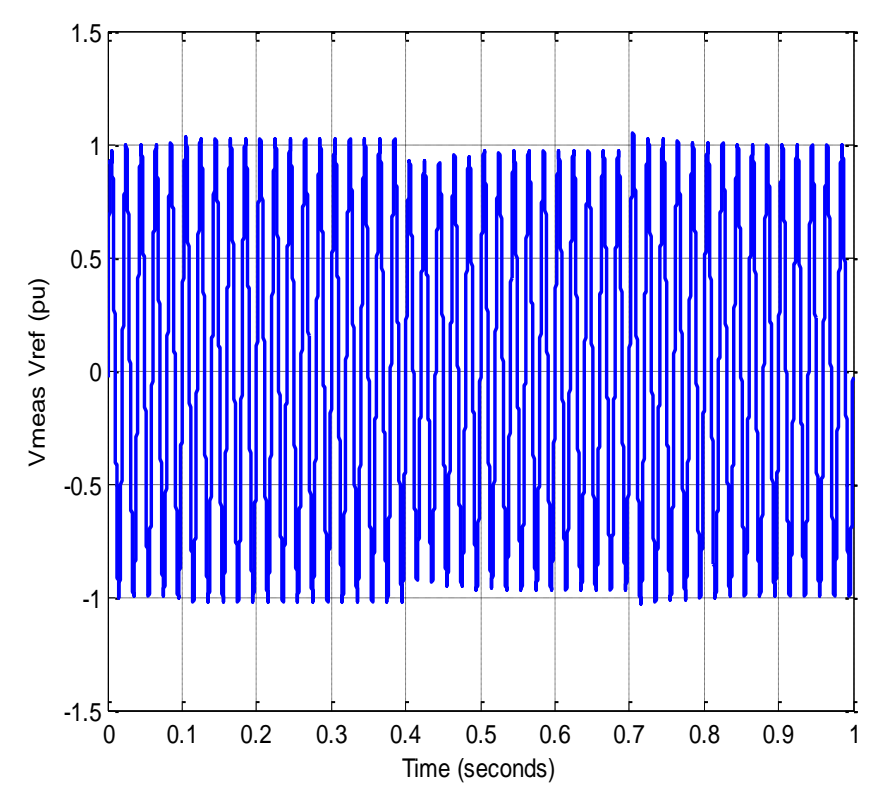

Figure 2: Primary Side Voltage of Transformer

From Fig.3, there was an increase in the amplitude of the current even up to $\pm 2.5 \mathrm{pu}$ at the time range of $0.4 .5 \mathrm{~s}$ to 0.7 .5 seconds due to the influence of the introduced disturbance. The reactive power absorbed increased even up to 96MVAR at time $\mathrm{t}=0.35 \mathrm{~s}$ before the compensation started at time $\mathrm{t}=0.4 \mathrm{~s}$ through $0.7 \mathrm{~s}$.

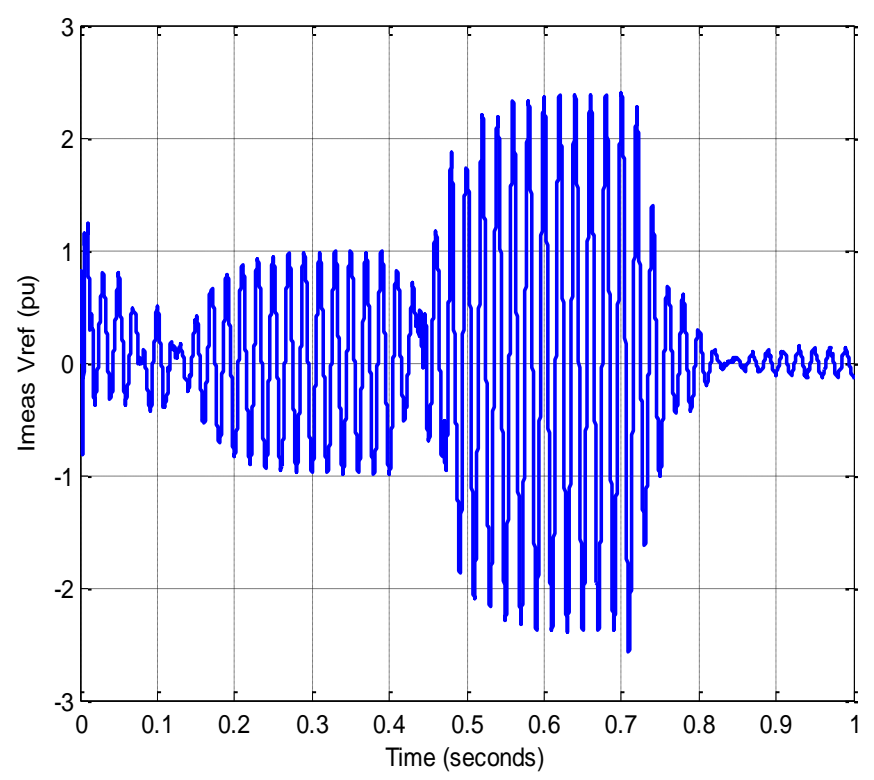

Fig.3: Primary Side Current of Transformer 
Critical observation of the graph illustrated by Fig. 4 shows that the reactive power compensated was up to 248MVAR before it started decreasing to zero at time $t=0.85 \mathrm{~s}$. This implies that the system is capacitive between time $0.12 \mathrm{~s}$ to $0.45 \mathrm{~s}$ and inductive from $0.46 \mathrm{~s}$ to $0.85 \mathrm{~s}$.

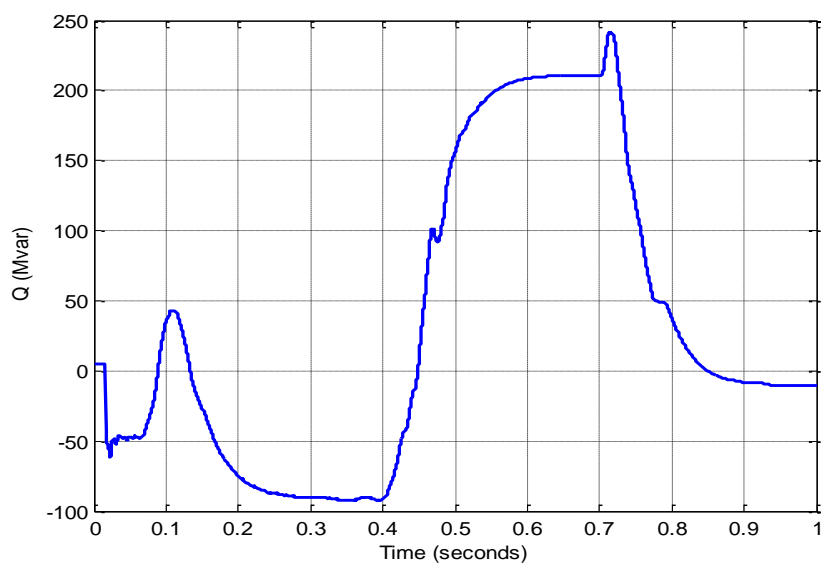

Fig. 4: Primary Side Reactive of Transformer

Also, Fig. 5 revealed that the reference voltage first decrease up to $0.95 \mathrm{pu}$ at time $\mathrm{t}=$ $0.04 \mathrm{~s}$ before it started fluctuating even up to time $\mathrm{t}$ $=0.8 \mathrm{~s}$ before it maintained stability up to time $\mathrm{t}=$ $1 \mathrm{~s}$. The system experienced a great disturbance from time $\mathrm{t}=0.4 \mathrm{~s}$ to $0.7 \mathrm{~s}$; making the per unit value of the voltage to decrease up to $0.917 \mathrm{pu}$ according to the graph in Fig 5. Each time the Thyristor-switched capacitor was switched on the thyristor-controlled reactor alpha angle changes suddenly from 180 degrees (no conduction) to 90 degrees (full conduction), as shown in Fig. 5.

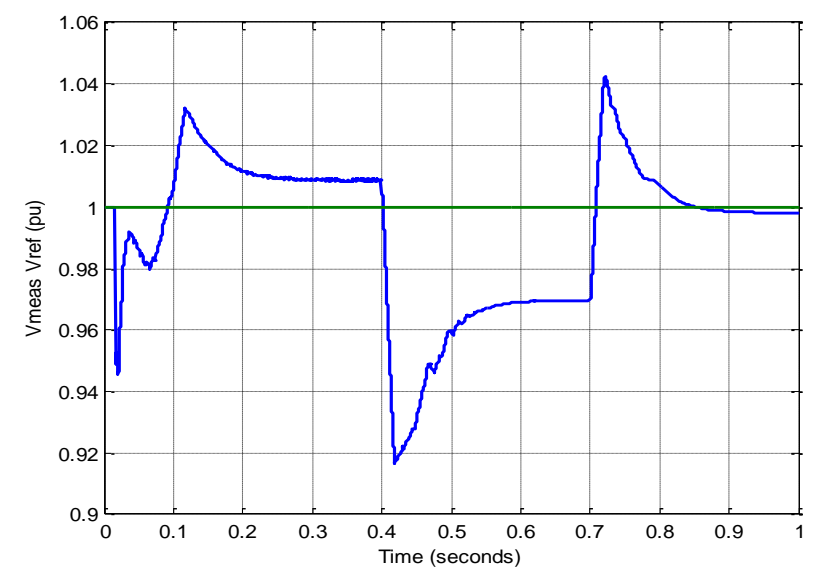

Fig.4: Average Voltage and Reference Voltage

Looking at Figure 6, every time a thyristor-switched capacitor is put into work, the thyristor-controlled reactor alpha angle suddenly changed from 100 degrees (conduction) to 180 degrees (non-conduction). However, when the thyristor-switched capacitor is switch off, the thyristor-controlled Reactor alpha angle suddenly changed from 180 degrees (no conduction) to 100 degrees (conduction).

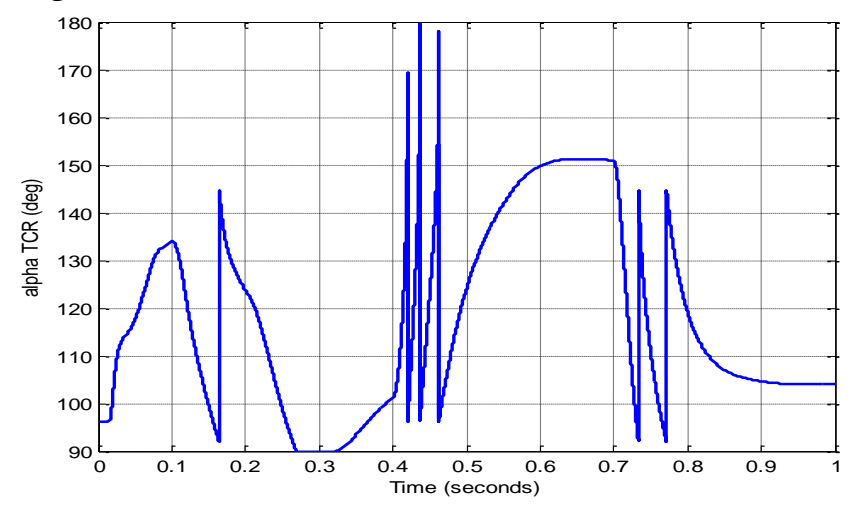

Fig. 6: Triggering Angle of Thyristor-controlled Reactor

From the graph of Fig. 7, it is observed that capacitor 1 was switched off at $0.14 \mathrm{~s}$ before it was restored at $0.42 \mathrm{~s}$. Also, at time $\mathrm{t}=0.43 \mathrm{~s}$, all the three capacitors were in action to stabilize the transmission line even up to time $0.7 \mathrm{~s}$ before two of those capacitor were switched off leaving only one capacitor to compensate for the remaining time.

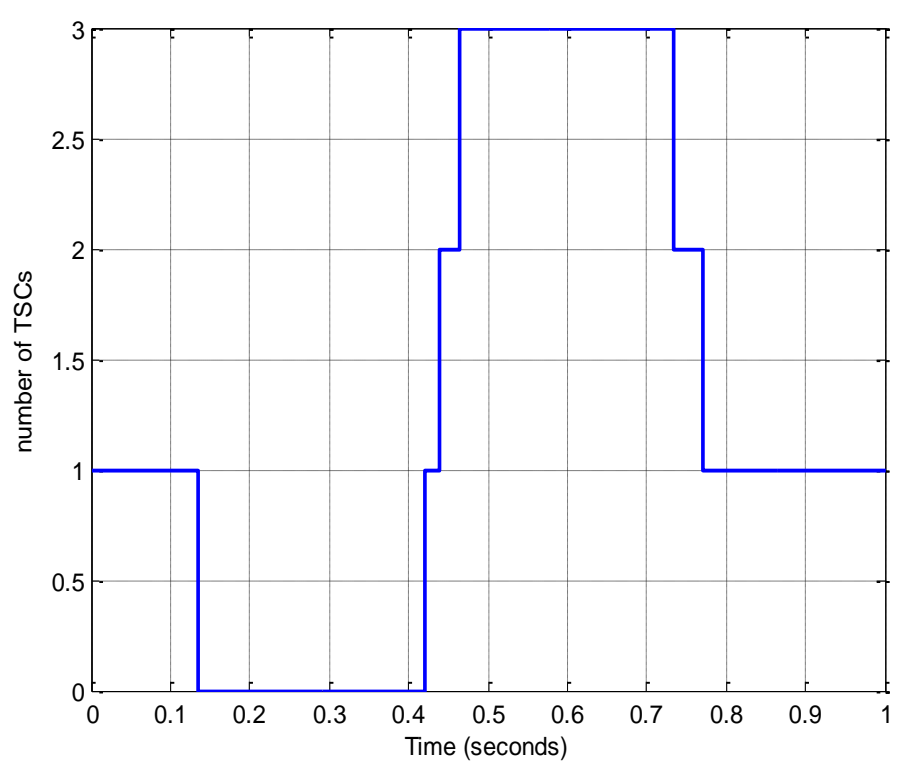

Figure5: Numbers of Thyristor-controlled Reactor Conduction

\section{Conclusion}

This paper presents application of autoswitched capacitor bank to mitigate voltage collapse problem on distribution system; a case study of Osogbo South-Western, Nigeria. Mathematical computation of reactive power required was done with current operating power 
factor raised to close unity with a view to determine and design the size of capacitor bank required to improve the voltage level of a $132 / 33 \mathrm{kV}$ substation with respect to its maximum load. Simulink modelling of the developed power system was done. The modelled system was subjected to disturbance, the behaviour of the system was critically observed, analyzed and graphical presentation was made.

A logical conclusion can be drawn that addition of correct size of capacitor bank helped to improve the voltage profile aimed at preventing system collapse due to overloading, line faults or high demand of reactive power demand when the system is inductive in nature. With this, it is hoped that if any of the capacitors or all the capacitor is switched-on Oshogbo transmission station which is $248 \mathrm{MVA} / 33 \mathrm{kV}$ should be able to handle more loads. Likewise, with the use of a thyristor switched controller for the banks switching device, capacitor banks like Static Var Compensator (SVC) can help to prevent system collapse. Future work can embark on investigating the efficiency of the proposed approach using another different study location within Nigeria.

\section{References}

[1] Hessamoddin, J.M. "Fault location in high voltage shunt capacitor banks. A thesis submitted in partial fulfillment of the requirements for the degree in Doctor of Philosophy, The University of Western Ontario, 2017.

[2] Olabode, O.E., Arowolo M.P., and Olugbemi A.O. "Optimal allocation and sizing of reactive power source for voltage profile improvement on Nigerian 330kV, 24-bus grid system". IOSR Journal of Electrical and Electronics Engineering,11(5), 40-48, 2016.

[3] Iyer, S. R., Ramachandran, K., and Hariharan, S. "Optimal reactive power allocation for improved system performance". IEEE Transactions on Power Apparatus and Systems, 3, 67-75, 1984.
[4] Su, H.Y. "An efficient approach for fast and accurate voltage stability margin computation in large power grids". Appl. Sci. 6, 335, 2016.

[5] Joshi, S., Kumar, S., and Joshi, S. K."Computational approaches for monitoring voltage stability in power networks". International Journal of Innovative Research in Advanced Engineering, 3(11), 25-30, 2016.

[6] Su, H.Y. and Liu, C.W. "Estimating the voltage stability margin using PMU measurements". IEEE Trans. Power Syst., 31, 3221-3229, 2016.

[7] Kessel, P., and Glavitsch, H. "Estimating the voltage stability of a power system". IEEE Trans. Power Deliv.,1,346354, 1986.

[8] ABB-automatic power factor correction capacitors in a harmonic environment, pp $1-3$

[9] Ali, M. and Repalle, S.C. (2014). Power factor correction. Experiment Report of Advanced Power Electronics APE 04, $1-16$.

\section{Author's Profile}

M.O.,Okelola is a Senior Lecturer in the department of Electronic \& Electrical Engineering, Ladoke Akintola University of Technology, Ogbomoso, Oyo State, Nigeria (LAUTECH). $\mathrm{He}$ is a registered engineer and holds Ph.D. (LAUTECH), M.Sc. (University of Lagos), B.Tech (LAUTECH) in Electronic \& Electrical Engineering. His research interests are in the areas of power quality and power system analysis. 